\section{"When I'm 64"}

$\mathrm{W}$

hy has longevity become a source of dismay rather than a cause for celebration? How did we turn the greatest triumph of 20th century public health and medicine into a problem for the 21 st century?

The nation's health bureaucrats and provincial health ministers insist an aging population will stress the health care system, if it doesn't cause its bankruptcy. Yes, we have an aging population. People are living later, not dying young, and this is a very good thing, not a problem.

The history of this alarmist demography is clear. It began with Erik K. Erikson's observation that, "an everincreasing number of old people were found to represent a mass of elderlies rather than an elite of elders." In 1987, Hastings Center ethicist Daniel Callahan saw this as a problem: society would be unable to afford pensions and health care for all these new oldsters. ${ }^{2}$ Colorado Gov. Richard D. Lamm enthusiastically agreed, famously arguing a "duty to die" to diminish costs of care for the frail and superannuated. ${ }^{3} \mathrm{Se}$ niors became "greedy geezers" and the race was on to make them scapegoats for a range of social ills. A new social discipline, gerontology, was born and geriatric medicine became a boardcertified specialty.

It is not that we can't afford senior care, but that we can't afford to be without these superannuated, socially active folk. They are active citizens who vote, volunteer and, in general, contribute more fully in many categories of social activity than younger folk.

Alarmist demographics like Callahan's and Lamm's are based on the statistical observation that, on average, care is more expensive in the last 6 months of a person's life than across prior decades of healthy life. Because seniors are statistically more likely to die sooner than younger folks - a

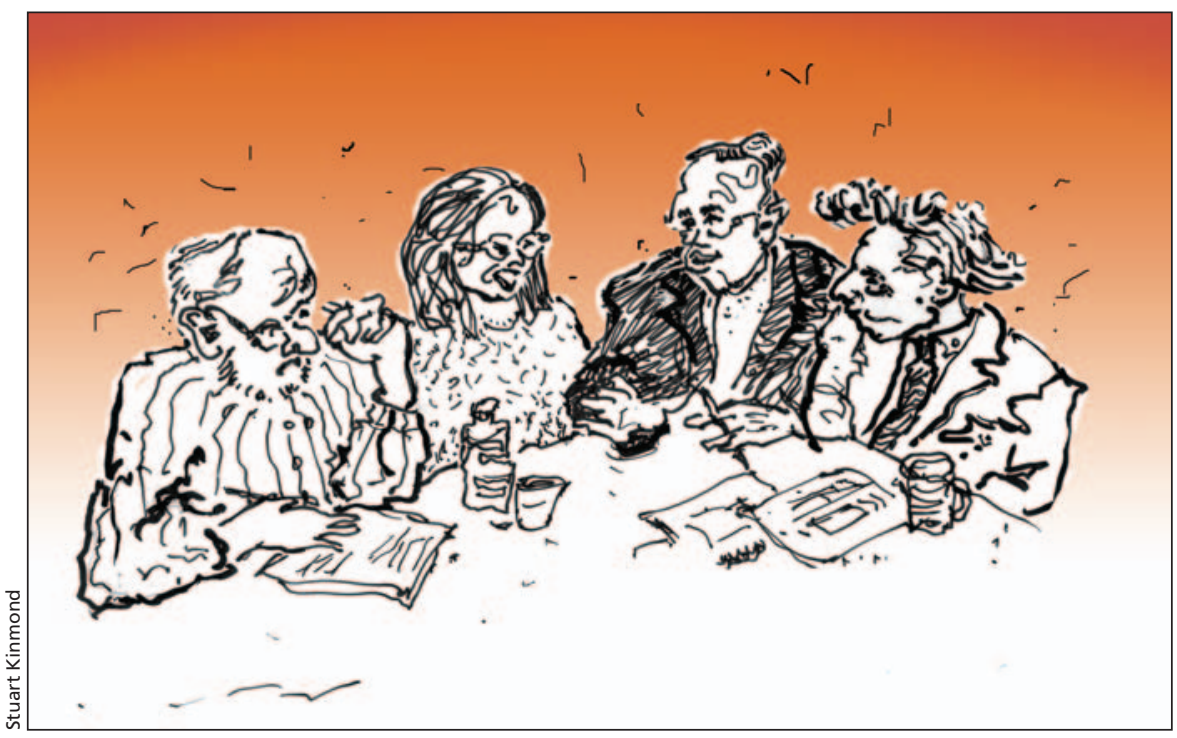

coarse actuarial conclusion - their care is more likely to be more expensive than that of younger persons.

This is a "default assumption," one that reflexively promotes unjustified assumptions. It is incorrect not only because many seniors require little care but also because many others require more. Caring for the average, over-65year-old senior is less costly than caring for non-geriatric patients with HIV, with juvenile rheumatoid arthritis, or a host of other chronic complaints; it is less costly than the average middleaged transplant. Organ transplantation normally benefits the young, not the old, and nothing is more expensive than this procedure whose after-surgery costs often exceed those of the surgery itself. Care for the average senior is not a patch on that required by low-birthweight infants, or those requiring neonatal surgery and extensive postoperative attention.

None of this is to suggest geriatric medicine is anything but critically important. It is to suggest that much of what we think of as geriatric is in fact medicine for fragile persons. Geriatric expertise in the maintenance of people with multiple conditions can serve the critically ill of every age.

Blaming people who are over the age of 65 for the rising costs of our publicly funded health care systems permits us to focus on one class of patients. In truth, health care is expensive at every age and not something to be begrudged anyone because of age. The alternative is that we should all die young, at the first hint of illness, or figure out how to live healthily and forever.

\section{Tom Koch PhD}

Bioethicist

Vancouver, BC

\section{REFERENCES}

1. Erikson EK. The Life Cycle Completed. New York: Norton; 1982.

2. Callahan D. Setting medical limits: medical goals for an aging society. New York: Simon and Schuster; 1987

3. Lamm R D. Columbus and Copernicus: New wine in old wineskins. Mt. Sinai J Med 1989;56:23.

Have you got an opinion about this article? Post your views at www.cmaj.ca. Potential Salon contributors are welcome to send a query to salon@ cma.ca. 